\title{
Ectomorphic and Endomorphic Personality: A Study of Emotional Quotient among Women
}

\author{
Urvashi Sharma*, Dr. Ravindra Kumar**
}

\begin{abstract}
The main objective of the present study is to examine the Emotional Quotient (sensitivity, conscientiousness, empathy and adaptability) among ectomorphic and endomorphic personality women. A sample of 30 participants (15 ectomorphy personality \& 15 Endomorphic personality types) was drawn randomly from the population. Emotional quotient scale by Prof. N. K. Chadha was used for data collection. Data was collected by a face to face interview method. Mean, standard deviation and ' $t$ ' test were the statistics calculated. The results indicate that there is no significant difference between ectomorphic and endomorphic women in relation to sensitivity, conscientiousness, empathy and adaptability. Results revealed that ectomorphic women have higher sensitivity, empathy and adaptability. On the other hand, the endomorphic women have higher conscientiousness.
\end{abstract}

KEYWORDS: Personality, Ectomorphic personality, endomorphic personality, emotional quotient, sensitivity, sensitivity, conscientiousness, empathy and adaptability

\section{INTRODUCTION}

Concept of Emotions \& Emotional Quotient: Emotions are the internal events that coordinate many psychological subsystems including psychological response, cognitions and conscious awareness. They are being viewed as signals that provide Information direct attention and facilitate attainment of goal and are seen as organizing processes that enable people to think and behave adoptively. Emotion Quotient (EQ) is the measurement of EI, EQ measures skills those-

*Student, PGDGCP, Indian Institute of Psychology, Noida (U.P.) INDIA

**Assistant Professor, Department of Psychology, Mewar University, Chittorgarh (Rajasthan) 
cognition and ones emotions in solving problems that confront you. EQ can be learned, developed and improved. EQ decides how you interact with people in your life. It therefore has a profound bearing on both your success and happiness. A person with high EQ will know how to make an individual work by appealing to his emotions and reason. Goleman summarized five E.Q. domains:

- Knowing your Emotions

- Managing your Emotions

- Motivating your Emotions

- Recognized and understanding other people Emotions

- Managing relationship EI managing the Emotion others

The main foundation of EQ includes self awareness optimism and empathy which may develop early in life. Other foundation of EQ developed only through experience such as perception, Persuasiveness and tact. EQ approach helps an individual to reach out of their fullest emotional potential. Right IQ guides, individual towards processing the right values behavior and emotion. The right emotional Intelligence, IQ in business and life can be understood by a four corner stone. Model explains by Copper (1997) this model assumes EI as out of the realm of psychological analysis and philosophical theories and moves into the realm of direct knowing exploration and application.

Concept of Personality: In the 1940's William Herbert Sheldon associated body types with human temperament types. He claimed that a body type could be linked with the personality of that person. He says that a fat person with a long bone structure tends to have an outgoing and more relaxed personality. While a more muscular body typed person is more active and aggressive. A slim or scrawny personality with thin muscles is usually characterized a quiet or fragile, he split up these body personality types into three categorized called somato types. Sheldon has categorized the following types of personality:

(i) Ectomorphic Personality: An Ectomorphic is the complete opposite of the endomorphic physically they have narrow shoulders, thin legs and arms, little fat on the body, a narrow face and narrow chest. They may eat just as much as the endomorphic but never seem to gain any weight. They always stay skinny personality wise. They tend to be self-conscious socially anxious, artistic, thoughtful, quiet and selves and are an afraid to branch out. 
(ii) Mesomorphic Personality: The Mesomorphic is between the endomorphic and thin ectomorphy. They have an attractive and desirable body physically they tend to have a large head and broad shoulders with a narrow waist. They have a strong muscular body and strong arms and legs and little fat on the body. They work for the body they have so that they could have an attractive body psychologically the Mesomorphic is adventurous and courageous. They are not afraid to break out and do new things with new people they are assertive and commutative and have a desire to have power and be dominant they love taking risks and chance in life.

(iii) Endomorphic Personality: An endomorphic somato types is also known as a niscerotonic. The characteristic trait of these somato types usually includes being relaxed, tolerant, comfortable and sociable, psychologically. They are also funloving-good humored even tempered and they love food and affection: The Endomorphic is physically round. They have wide a hips and narrow shoulders that give pears nape. They tend to have a lot of extra fat on their body on their arms and things. They have skinny ankles and wrists that make the rest of their body look even bigger.

\section{OBJECTIVES OF STUDY}

The objectives of the present study are to examine the Sensitivity, Conscientiousness, Empathy and Adaptability among Ectomorphic and Endomorphic personality women.

\section{HYPOTHESIS OF THE STUDY}

$\mathbf{H}_{\mathbf{0}} 1$. There is no significant different among Ectomorphic and Endomorphic personality women in relation to sensitive.

$\mathbf{H}_{0}$ 2. There is no significant among Ectomorphic and Endomorphic personality women in relation to Conscientiousness.

$\mathbf{H}_{0}$ 3. There is no significant difference among Ectomorphic and Endomorphic personality women in relation to Empathy.

$\mathbf{H}_{\mathbf{0}}$ 4. There is no significant difference among Ectomorphic and Endomorphic personality women in relation to Adoptability. 
The International Journal of Indian Psychology: Volume: 01 | Issue: 03 | ISSN 2348-5396

\section{RESEARCH METHODOLOGY}

\section{Sample:}

The sample consisted of 30 Ectomorphic and Endomorphic personality women (15 Ectomorphic \& 15 Endomorphic) from Ghaziabad city. Age range of women's 19 to 40 Years.

\section{TABLE I}

\section{Sample of Ectomorphic \& Endomorphic personality women}

\begin{tabular}{|l|l|l|l|}
\hline Sr. No. & Group & N & \multirow{2}{*}{ S } \\
\cline { 1 - 3 } 1 & Ectomorphic Women & 15 & \multirow{2}{*}{30} \\
\hline 2 & Endomorphic Women & 15 & \\
\hline
\end{tabular}

\section{Tools Used:}

Emotional Quotient Scale (Dr. N. K. Chadha): The E.Q. scale comprises seventy three items related four areas of Emotional viz. Sensitivity, Conscientiousness, Empathy and Adaptability. The responses to be given in four dimensions responses indicate Emotional intelligence. There is no time limit, yet it takes about one day to complete the test. It is a paper pencil questionnaire which can be administrated on an individual or a group of individuals. The scale has seventy three items test reliability was computed after a lapse of 6 weeks. The obtained was 0.89 and validity of the scale was obtained by correlating it with the Emotional Intelligence test developed by Chadha 2001 . The validity was found to be 0.78 which indicated that the present test is valid.

\section{Procedure of Data Collection:}

The inventories were distributed participants. The subjects were given general instruction to complete the inventory purpose of study was made clear to the participant help was provided to the participant in case. They found any of the items difficult to comprehend. Data was collected by face to face interview method filled questionnaires were collected from subject for further processing.

\section{Statistical Analysis of Data:}

In the present study mean, SD and T-test was applied for statistical analysis of data. 


\section{ANALYSIS AND INTERPRETATION}

The main objectives of the present study are to examine the EQ viz. Sensitivity, Conscientiousness, Adoptability and Empathy among Ectomorphic and Endomorphic personality women. Mean, S.D. and t-test was applied for statistical analyses of data.

\section{TABLE II}

Mean, S.D., t-value of Ectomorphic and Endomorphic personality women Sensitivity (S): Ectomorphic $\times$ Endomorphic

\begin{tabular}{|l|l|l|l|l|l|l|}
\hline Sr. No. & Group & N & Mean & S.D. & t-value & Sig \\
\hline 1 & Ectomorphic & 15 & 63.8 & 9.84 & \multirow{2}{*}{0.73} & \multirow{2}{*}{ N S } \\
\hline 2 & Endomorphic & 15 & 61.33 & 8.11 & & \\
\hline
\end{tabular}

The result indicate that Ectomorphic personality women have higher mean score in relation to sensitivity $(\mathrm{M}=63.8, \mathrm{SD}=9.84)$ in compared to Endomorphic personality women $(\mathrm{M}=61.33$, $\mathrm{SD}=8.11$ ). So we can say that Ectomorphic personality women have higher sensitivity in their personality but there is not found any significant difference $(\mathrm{t}=0.73)$ among ectomorphic endomorphic personality women in relation to sensitivity.

\section{TABLE III}

Mean, S.D., t-value of Ectomorphic and Endomorphic personality women Conscientiousness $(\mathrm{C})$ : Ectomorphic $\times$ Endomorphic

\begin{tabular}{|l|l|l|l|l|l|l|}
\hline Sr. No. & Group & N & Mean & S.D & t-value & Sig \\
\hline 1 & Ectomorphic & 15 & 45.93 & 8.2 & \multirow{2}{*}{0.08} & \multirow{2}{*}{ N S } \\
\hline 2 & Endomorphic & 15 & 46.2 & 9.38 & & \\
\hline
\end{tabular}

The result indicate that Endomorphic personality women have higher mean score in relation to Conscientiousness $(\mathrm{M}=46.2, \mathrm{SD}=9.38)$ in compared to Ectomorphic personality women $(\mathrm{M}=45.93, \mathrm{SD}=8.2)$. So we can say that Ectomorphic personality women have higher conscientiousness in their personality but there is not found any significant difference $(\mathrm{t}=0.08)$ among ectomorphic endomorphic personality women in relation to conscientiousness. 
The International Journal of Indian Psychology: Volume: 01 | Issue: 03 | ISSN 2348-5396

TABLE IV

Mean, S.D., t-value of Ectomorphic and Endomorphic personality women Empathy (E): Ectomorphic $\times$ Endomorphic

\begin{tabular}{|l|l|l|l|l|l|l|}
\hline Sr. No. & Group & N & Mean & S.D. & t-value & Sig \\
\hline 1 & Ectomorphic & 15 & 56.4 & 11.49 & \multirow{2}{*}{1.00} & \multirow{2}{*}{ N S } \\
\hline 2 & Endomorphic & 15 & 52.73 & 7.45 & & \\
\hline
\end{tabular}

The result indicate that Ectomorphic personality women have higher mean score in relation to Empathy $(\mathrm{M}=56.4, \mathrm{SD}=11.49)$ in compared to Endomorphic personality women $(\mathrm{M}=52.73$, $\mathrm{SD}=7.45$ ). So we can say that Ectomorphic personality women have higher Empathy in their personality but there is not found any significant difference $(\mathrm{t}=1.00)$ among ectomorphic endomorphic personality women in relation to Empathy.

\section{TABLE V}

Mean, S.D., t-value of Ectomorphic and Endomorphic personality women Adoptability (A): Ectomorphic $\times$ Endomorphic

\begin{tabular}{|c|c|c|c|c|c|c|}
\hline Sr. No. & Group & $\mathbf{N}$ & Mean & S.D. & $\mathbf{t}$ & Sig \\
\hline 1 & Ectomorphic & 15 & 43.13 & 5.6 & & \\
\hline 2 & Endomorphic & 15 & 40.95 & 6.18 & & \\
\hline
\end{tabular}

The result indicate that Ectomorphic personality women have higher mean score in relation to Adoptability $(\mathrm{M}=43.13, \mathrm{SD}=5.6)$ in compared to Endomorphic personality women $(\mathrm{M}=40.95$, $\mathrm{SD}=6.18)$. So we can say that Ectomorphic personality women have higher Adoptability in their personality but there is not found any significant difference $(\mathrm{t}=0.98)$ among ectomorphic endomorphic personality women in relation to Adoptability.

\section{RESULT AND DISCUSSION}

The research shows that the characteristics shown by individuals not matching with their physical structure as it were discussed by Sheldon in his personality theory. The main conclusion emerged from the analyses of data is that there is no significant difference of EQ (sensitivity, Empathy, Adoptability) among Ectomorphic and Endomorphic personality women. In simple terms it can be concluded that Ectomorphic personality women have higher sensitivity, Empathy 
and adoptability in their personality while Endomorphic women have higher conscientiousness in their personality.

\section{REFERENCES:}

1. Cooper, R and Sawaf, A. (1997) Executive EQ, New York, Orient Book.

2. Goleman, D (1995) Emotion Intelligence. Why it can matter more than IQ, New York, Banthan

3. Goleman, D (1995) Emotional Intelligence, New York. Bnathan Book

4. Herrnstein, R and Murray. C. (1994) The Ball Curve, Intelligence and class in American life, New York. Free press

5. https://sites.google.com/site/psychology personality period 8/home/type and traittheories/sheldon-s-personality-theory.

6. Mayur, Dipaola, M and Salovey. P. (1990) Perceiving affective context in ambiguous Vishal Stimuli, A component of Emotion Intelligence. Journal of Personality Assessment (54) pp- 770-81

7. Salovey. P. and Mayer. J. (1990) Emotion Intelligence Imagination, Cognition fand Personality 9 pp- 185-211 